\title{
Indocyanine green imaging for pulmonary segmentectomy
}

\author{
Masaya Yotsukura, MD, Yu Okubo, MD, Yukihiro Yoshida, MD, Kazuo Nakagawa, MD, and
}

Shun-ichi Watanabe, MD

\section{ABSTRACT}

Objective: Delineation of the intersegmental plane during pulmonary segmentectomy by systemic injection of indocyanine green (ICG) has been rapidly emerging. We evaluated the feasibility of the use of ICG in a large-scale cohort according to the type of segmentectomy and the presence of obstructive lung disorder and compared the demarcation status with air injection.

Methods: We collected the data of 209 patients who underwent segmentectomy using ICG at National Cancer Center Hospital, Tokyo, Japan. Data of the operation including the demarcation status of the intersegmental plane were analyzed retrospectively.

Results: The median operation duration and blood loss were 105 minutes (interquartile range, 94-118 minutes) and $12 \mathrm{~mL}$ (interquartile range, 5-24 mL), respectively. Good demarcation of the intersegmental plane by ICG was observed in 184 $(88.0 \%)$ cases, with no correlation to the type of resected segments or the presence of obstructive lung disorder. Postoperative complications of Clavien-Dindo classification grade 3 or more were observed in 5 cases $(2.4 \%)$, and no ICGrelated adverse event was noted. High-frequency jet ventilation was also used in 160 cases $(76.6 \%)$ to delineate the intersegmental inflation-deflation plane. The air injected by high-frequency jet ventilation tended to spread further beyond the intersegmental plane that was depicted by ICG.

Conclusions: The use of ICG might demarcate the intersegmental plane more restricted to the target segment compared with air injection. Delineation of the intersegmental plane by ICG is feasible regardless of the type of segmentectomy or the presence of obstructive lung disorder, and it can be commonly applicable in pulmonary segmentectomy. (JTCVS Techniques 2021;6:151-8)

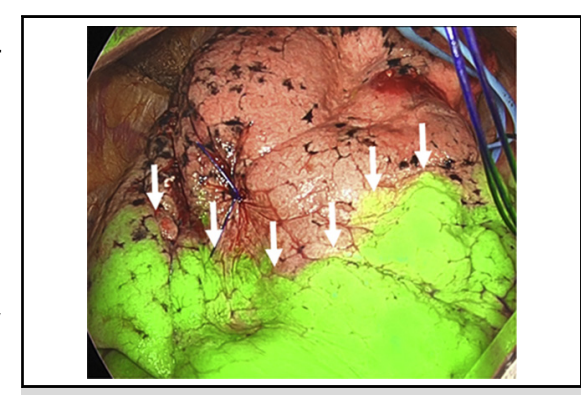

The use of ICG is a feasible and safe method to delineate intersegmental plane (arrows).

CENTRAL MESSAGE

The use of ICG is feasible and safe in lung segmentectomy, regardless of the type of segmentectomy or pulmonary function.

\begin{abstract}
PERSPECTIVE
Systemic injection of ICG has been rapidly emerging for the demarcation of intersegmental plane in lung segmentectomy. The use of ICG is a feasible and safe method regardless of the extent of resected segments or pulmonary function, and tend to show a more restricted intersegmental plane than jet ventilation.
\end{abstract}

See Commentaries on pages 159 and 161.
Video clip is available online.

Pulmonary segmentectomy is a procedure that aims to remove 1 or more segments of the lung that include the

\footnotetext{
From the Department of Thoracic Surgery, National Cancer Center Hospital, Tokyo, Japan.

This work was supported in part by Japan Agency for Medical Research and Development (AMED) grant number 19ck0106323h003 (to S.I.W.).

Received for publication Dec 21, 2020; accepted for publication Dec 21, 2020; available ahead of print Jan 6, 2021.

Address for reprints: Shun-ichi Watanabe, MD, Department of Thoracic Surgery, National Cancer Center Hospital, 5-1-1 Tsukiji, Chuo-ku, Tokyo 104-0045, Japan (E-mail: syuwatan@ncc.go.jp).

2666-2507

Copyright (C) 2021 The Authors. Published by Elsevier Inc. on behalf of The American Association for Thoracic Surgery. This is an open access article under the CC BY-NCND license (http://creativecommons.org/licenses/by-nc-nd/4.0/).

https://doi.org/10.1016/j.xjtc.2020.12.005
}

disease lesion while leaving the normal lung intact. Compared with lobectomy, segmentectomy is expected to have a benefit of preserved pulmonary function, with an adequate disease-controlling effect. Especially for lung cancer, segmentectomy is expected to replace lobectomy as a standard method of resection for small-sized nonsmall cell lung cancer (NSCLC) with ground-glass opacity (GGO) on computed tomography.

At present, the Japan Clinical Oncology Group (JCOG) is conducting 2 clinical trials regarding segmentectomy for lung cancer. ${ }^{1}$ JCOG 0802 is a Phase III study to evaluate the noninferiority in overall survival of segmentectomy compared with lobectomy in patients with small-sized (diameter $\leq 2.0 \mathrm{~cm}$ ) peripheral NSCLC excluding radiologically determined noninvasive cancer. JCOG 1211 is a confirmatory trial of segmentectomy for predominant GGO lung adenocarcinoma $\leq 3.0 \mathrm{~cm}$ in diameter based on thin-section computed tomography. Depending on the 


\section{Abbreviations and Acronym \\ FEV1 = forced expiratory volume in 1 second \\ $\mathrm{FVC}=$ forced vital capacity \\ GGO = ground-glass opacity \\ HFJV = high-frequency jet ventilation system \\ ICG = indocyanine green \\ JCOG = Japan Clinical Oncology Group \\ NSCLC $=$ non-small cell lung cancer}

results of these clinical trials, segmentectomy has possibility to have a position of one of the standard operative procedures for selected lung cancer.

During a segmentectomy operation, surgeons have used several kinds of methods to determine the intersegmental plane of the lung. ${ }^{2}$ It has been common to inflate the whole lung after occlusion of the target segmental bronchus or to inflate the target segmental bronchus only. The ability of this method for identifying the intersegmental plane has not been not always satisfactory, ${ }^{2,3}$ and thus delineation of the predicted intersegmental plane by systemic injection of indocyanine green (ICG) under near-infrared fluorescence imaging has been rapidly emerging over the past few several years. ${ }^{4,5}$ To date, studies on the feasibility of the use of ICG for identifying the intersegmental plane during pulmonary segmentectomy have been conducted in only small groups of subjects. ${ }^{4,6-8}$ In this study, we evaluated the feasibility of segmentectomy using ICG in a large cohort.

\section{METHODS \\ Patient Collection}

Of the 996 patients who underwent pulmonary resection between September 2018 and December 2019 at National Cancer Center Hospital, Tokyo, Japan, we retrospectively collected data of 244 patients who underwent segmentectomy. Of these patients, those who had incomplete resection $(\mathrm{n}=2)$ or who underwent segmentectomy without using ICG injection due to the unavailability of instruments for the use of ICG $(n=33)$ were excluded. Consequently, 209 patients were included in this study.

The indications for segmentectomy in patients with lung cancer were principally based on the enrollment criteria in JCOG 0802 (small [diameter $\leq 2.0 \mathrm{~cm}$ ] peripheral NSCLC excluding radiologically determined noninvasive cancer) and JCOG 1211 (predominant GGO lung adenocarcinoma $\leq 3.0 \mathrm{~cm}$ in diameter).

Complete resection was defined as the resection of all macroscopic tumor tissue and a resection margin that was free of tumor cells upon microscopic analysis. For lung cancer, the clinical stage was determined according to the tumor-node-metastasis criteria from the 8th edition of the Union for International Cancer Control Classification. Histologic evaluation was performed according to the 4th edition of the World Health Organization classification of lung tumors. All clinical information was retrospectively extracted from the patients' medical records.

\section{Operative Procedure}

In this study, simple segmentectomy was defined as upper-division (left $\mathrm{S} 1+2$ and S3), lingular (left S4 +5 ), superior (S6), or basilar segmentectomy. Complex segmentectomy was defined as individual or bisegmentectomy other than upper-division or lingular segmentectomy.

Pulmonary segmentectomy was performed via the open approach, in combination with the use of a thoracoscope. ${ }^{9}$ In most cases, skin incisions of 5 to $8 \mathrm{~cm}$ for thoracotomy at the fourth or fifth intercostal space, and of $1.5 \mathrm{~cm}$ for a thoracoscope at the seventh or eighth intercostal space were made.

During the operation, the target segmental pulmonary arteries, veins, and bronchus were divided by either ligation or a surgical stapler. In principle, pulmonary arteries were divided first, followed by division of the bronchus, although the sequence of dividing these vessels and bronchus were dependent on the situation.

Optionally, lung inflation through the target segmental bronchus using a high-frequency jet ventilation system (HFJV) was performed before dividing the bronchus, to depict the inflation-deflation line, when the surgeon judged it would be beneficial for identifying the intersegmental plane. To perform HFJV, a bronchoscope was placed through the double-lumen tube into the target bronchus. High-frequency oscillation was then started (9 Hz, working pressure $2 \mathrm{~kg} / \mathrm{cm}^{2}$, MERA Jet Ventilator JP-1; Senko Medical Instrument Mfg Co, Ltd, Tokyo, Japan). The inflation-deflation line was formed when the target segment was inflated while the preserved segments remained collapsed. After division of all the target segmental pulmonary arteries and bronchus, ICG was injected intravenously.

ICG was reconstituted into distilled water to produce a $2.5 \mathrm{mg} / \mathrm{mL}$ solution, and a volume of $0.25 \mathrm{mg} / \mathrm{kg}$ was injected into the peripheral vein, ${ }^{10,11}$ followed by a $10-\mathrm{mL}$ flush of sterile normal saline. After injection, the surgical field was visualized by near-infrared fluorescence imaging using a fluorescence imaging camera (1588 or 1688 AIM Camera System, Stryker, Kalamazoo, Mich). The target segment, which was already isolated from the pulmonary vasculature, exhibited no fluorescence. The perfused ICG allowed the remainder of the lung to become fluorescent green. The intersegmental plane was then identified as the line separating the nonfluorescent and fluorescent lung parenchyma. The depicted plane was marked by either electrocautery or a surgical marker. When the intersegmental plane was delineated by a continuous line on the surface of the lung, it was regarded as "good" demarcation. In contrast, when the intersegmental plane was not delineated by a continuous line, it was regarded as "poor" demarcation.

Representative demarcations of the intersegmental plane are shown in Figures 1 and 2, and the Video 1. Times from injection of ICG to the beginning of visualization of the intersegmental plane, maximum visualization, and disappearance of the plane were evaluated by at least 2 surgeons.

When HFJV was used before division of the bronchus, the shortest distance between the inflation-deflation line and the point marked according to the fluorescent area was measured (Figure 3).

Based on the intersegmental plane depicted by ICG fluorescence, combined with the information regarding the location of the pulmonary vein and inflation-deflation line if available, the intersegmental plane was divided using surgical staplers, and segmentectomy was completed.

After segmentectomy, the presence of an air leak from the lung parenchyma or bronchus closure line was searched by inflation of the lung under water. If an air leak was observed, it was managed by manual sutures, fibrin sealant patch, polyglycolic acid sheet, and/or fibrin glue. After that, the lung was inflated again under water to confirm that there was no longer an obvious air leak. A 28-Fr chest tube was placed through the incision for the thoracoscope.

\section{Postoperative Care}

The chest tube was subjected to controlled suction of $-10 \mathrm{~cm} \mathrm{H}_{2} \mathrm{O}$ on the day of the operation and this was switched to $-5 \mathrm{~cm} \mathrm{H}_{2} \mathrm{O}$ on the first postoperative day; this was continued until removal of the chest tube. When the lung was not adequately expanded, suction of $-10 \mathrm{~cm} \mathrm{H}_{2} \mathrm{O}$ was continued to allow further expansion. The chest tube was removed on postoperative day 1, provided the amount of drainage was $<200 \mathrm{~mL}$ and there had been no air leakage for the past 12 hours. 

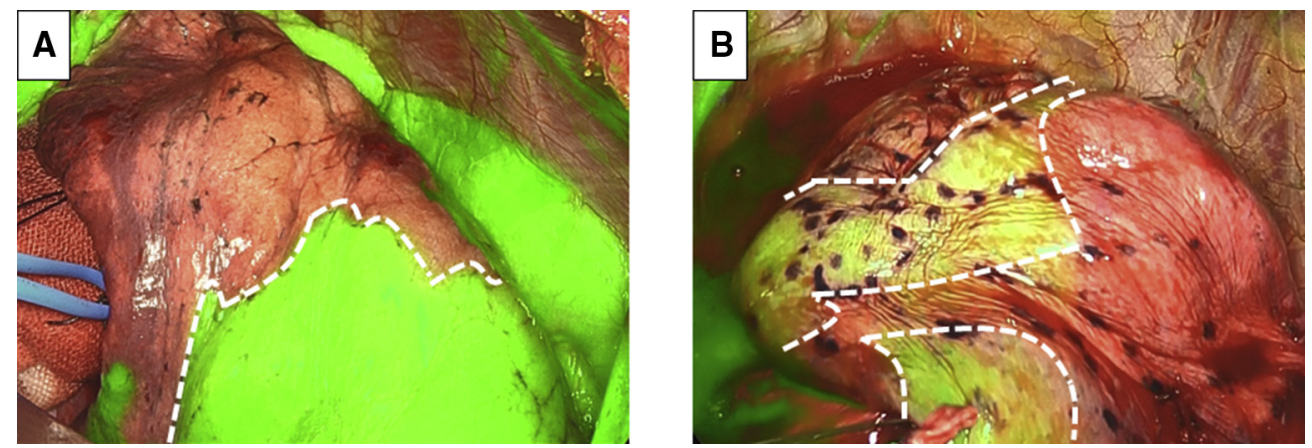

FIGURE 1. Examples of good and poor demarcation of the intersegmental plane by systemic injection of indocyanine green under near-infrared imaging. In a good-demarcation case (a case of right superior segmentectomy), the intersegmental plane (dashed line) is clearly depicted under near-infrared imaging. A segment to be resected is not observed in green, as the target pulmonary artery is already divided, whereas segments to be retained appear in green under near-infrared imaging (A). In a poor-demarcation case (a case of right S3 segmentectomy), the border between segments (dashed line) is not well defined (B).

Postoperative complications were recorded according to the ClavienDindo classification of surgical complications. ${ }^{12}$ As long as complications that would require hospitalized care were not present, the patient was discharged 2 days after removal of the chest drainage tube.

\section{Statistical Analysis}

The data are presented as means, medians, or counts and percentages, as appropriate. The clinical and surgical variables were compared among the groups, simple segmentectomy versus complex segmentectomy, and the presence versus absence of obstructive lung disorder.

The presence or absence of obstructive lung disorder was substituted by the value of forced expiratory volume in 1 second/forced vital capacity (FEV1/FVC), with a threshold of $70 \%$, based on the most commonly fixed cut-off values, including the American Thoracic Society and European Respiratory Society criteria. ${ }^{13}$

The average values of variables were evaluated using Student $t$ test or the Mann-Whitney $U$ test, as appropriate. For the statistical analyses of the relationships between the groups, Pearson's test was used. All tests were 2-sided. All statistical analyses were performed using SPSS 22.0 software (IBM Corp, Armonk, NY).

\section{Ethical Approval}

This retrospective study was approved by the National Cancer Center Review Board (research number 2018-045). The research was conducted in accordance with the 1964 Declaration of Helsinki and its later amendments.

\section{RESULTS \\ Patient Characteristics}

Characteristics of the enrolled patients are shown in Table 1. Of the 209 patients, $122(58.4 \%)$ were female and $122(52.2 \%)$ had a smoking habit, with a median Brinkman Index for smokers of 528 (range, 5-2160). The average age at operation was $67.9 \pm 11.6$ years. The average percentage predicted forced vital capacity $(\% \mathrm{FVC})$, FEV1/ FVC, and percentage predicted forced expiratory volume in 1 second (predicted \%FEV1) were $110.3 \pm 7.2 \%$, $75.1 \pm 7.8 \%$, and $110.2 \pm 20.5 \%$, respectively.

\section{Operation Details}

Details of the operation and perioperative outcomes are shown in Table 2. The most frequent type of segmentectomy was right superior (S6) resection (31 cases, 14.8\%), followed by left upper division (S1 $+2+3)$ segmentectomy (27 cases, $12.9 \%$ ). Bisegmentectomy was performed
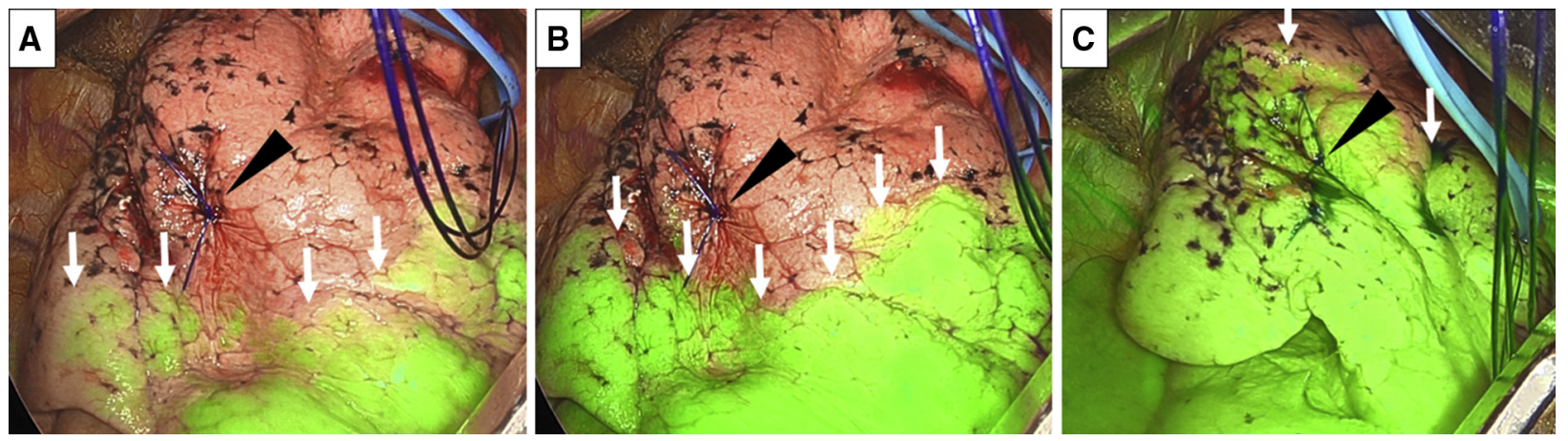

FIGURE 2. Expression of the intersegmental plane by systemic injection of ICG under near-infrared imaging in right S1 segmentectomy. The location of the tumor is marked by a nylon suture (arrowhead). After the systemic injection of ICG, an intersegmental plane (arrow) begins to be highlighted within 10 to 20 seconds in most cases (A). The depiction of the intersegmental plane (arrow) reaches the maximum level within 30 to 50 seconds in most cases after the systemic injection of ICG. The location of this maximally visualized intersegmental plane is marked by a surgical marker or electrocautery, to determine the intersegmental division line (B). The intersegmental plane (arrow) disappears within 70 to 120 seconds in most cases (C). 


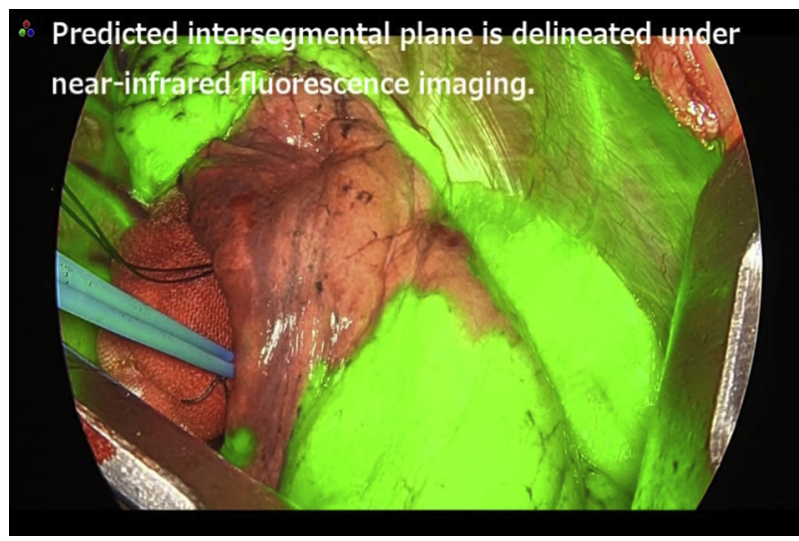

VIDEO 1. Mapping of the intersegmental plane using indocyanine green. This video demonstrates demarcation of the intersegmental plane after systemic injection of indocyanine green. Under near-infrared fluorescence imaging, lung that should be left behind becomes fluorescent green. The fluorescent area then gradually extends to the target segment, and the depicted intersegmental plane becomes obscure. Based on this observation, the surgeon marks the predicted intersegmental plane using a surgical marker. Video available at: https://www.jtcvs.org/article/S2666-2507(20) 30772-0/fulltext.

in 17 cases $(8.1 \%)$, in which the most common procedure was $\mathrm{S} 8+9$ bisegmentectomy ( 5 cases, $2.4 \%$ ). Subsegmentectomy was performed in 5 cases $(2.4 \%)$.

The median operation duration was 105 minutes (range, 68-189 minutes). The median amount of blood loss was $12 \mathrm{~mL}$ (range, 0-366 mL).

Good demarcation of the predicted intersegmental plane by ICG was observed in 184 cases $(88.0 \%)$. Median times from intravenous injection of ICG to intersegmental plane detection, maximum visualization, and disappearance were 15 (range, 3-60), 40 (range, 10-155), and 90 seconds (range, 30-420), respectively. HFJV was also used in 160

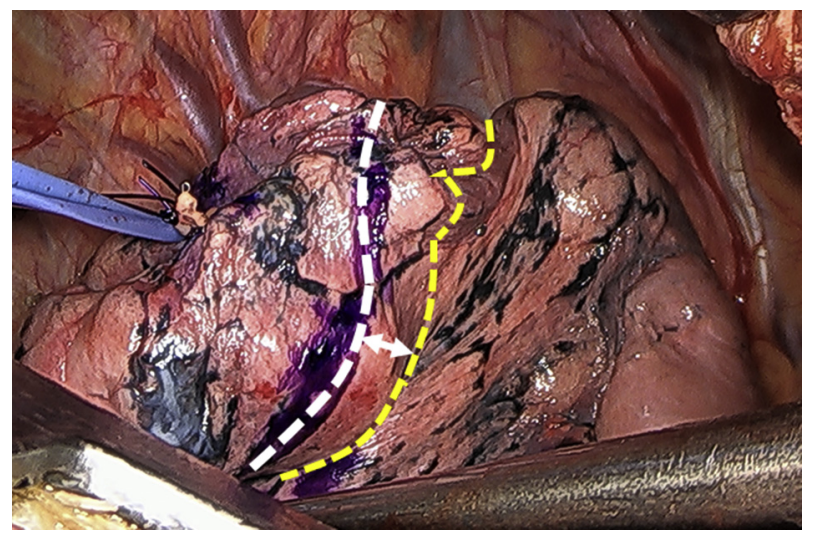

FIGURE 3. When high-frequency jet ventilation was used before division of the bronchus, the shortest distance between the inflation-deflation line presented by high-frequency jet ventilation (yellow dashed line) and the point marked according to the fluorescent area (white dashed line) was measured (arrow).
TABLE 1. Characteristics of enrolled patients $(n=209)$

\begin{tabular}{lc}
\hline \multicolumn{1}{c}{ Characteristic } & Value \\
\hline Age at operation, y, mean \pm SD & $67.9 \pm 11.6$ \\
Sex, female/male $(\%)$ & $122(58.4) / 87(41.6)$ \\
Smoking habit, present/absent ( $\%)$ & $109(52.2) / 100(47.8)$ \\
$\begin{array}{l}\text { Brinkman Index for past or current smokers, } \\
\quad \text { median (range) }\end{array}$ & $528(5-2160)$ \\
Preoperative percent predicted FVC, mean \pm SD & $110.3 \pm 17.2$ \\
Preoperative FEV1/FVC, mean \pm SD & $75.1 \pm 7.8$ \\
Preoperative percent predicted FEV1, & $110.2 \pm 20.5$ \\
$\quad$ mean \pm SD & \\
\hline $\begin{array}{l}\text { SD, Standard deviation; } F V C, \text { forced vital capacity; FEV1, forced expiratory volume } \\
\text { in } 1 \text { s. }\end{array}$
\end{tabular}

cases $(76.6 \%)$, among which good demarcation of the inflation-deflation line was observed in 126 cases (78.7\%). The median distance between HFJV and the ICG-related intersegmental plane was $+13 \mathrm{~mm}$ (range: -18 to +75 ), which meant that HFJV tended to show a larger area of the target segment compared with ICG.

To regulate the air leak from lung parenchyma at the end of the operation, we used fibrin sealant patch in 7 cases $(3.3 \%)$. The median postoperative dates of chest tube removal and discharge from hospital were day 1 (range, 1-26) and day 3 (range, 2-28), respectively. The number of cases with prolonged air leak (more than 5 days after surgery) was $8(3.8 \%)$. Postoperative complications with a Clavien-Dindo grade of 3 or more developed in 5 patients $(2.4 \%)$. None of the complications were related to ICG.

\section{Resected Tumor}

Details of the resected lesion are shown in Table 3. Of the 209 enrolled patients, $179(85.6 \%)$ had lung adenocarcinoma. Twelve patients $(5.7 \%)$ had metastatic pulmonary tumor, $6(2.9 \%)$ had benign lesion, and $5(2.4 \%)$ had squamous cell lung cancer. The median radiological and pathological total lesion sizes were $18 \mathrm{~mm}$ (range, 5-66 mm) and $18 \mathrm{~mm}$ (range, 6-73 mm), respectively. As for lung cancer, the most common pathologic stage for lung cancer was T1bN0M0 (64 cases, $34.4 \%$ ), followed by T1aNOM0 (46 cases, $24.7 \%$ ).

\section{Comparison of Simple and Complex Segmentectomy}

There were no significant differences between simple and complex segmentectomy with respect to sex, smoking habit, operation duration, blood loss, preoperative pulmonary function, or postoperative complications. The margin distance in simple segmentectomy was longer than that in complex segmentectomy $(27.0 \pm 14.9$ vs $21.0 \pm 10.0 \mathrm{~mm}, P=.004)$. Detection of the inflation-deflation line was worse in complex segmentectomy $(P=.033)$. The times from intravenous injection of ICG to detection of the intersegmental plane and 
TABLE 2. Operation details and perioperative outcomes

\begin{tabular}{|c|c|}
\hline Characteristic & Value \\
\hline \multicolumn{2}{|l|}{ Resected segment, n (\%) } \\
\hline \multicolumn{2}{|l|}{ Right } \\
\hline \multirow[t]{2}{*}{$\mathrm{S} 1 / \mathrm{S} 2 / \mathrm{S} 3 / \mathrm{S} 6 / \mathrm{S} 8$} & $21(10.0) / 17(8.1) /$ \\
\hline & $10(4.8) / 31(14.8) / 10(4.8)$ \\
\hline S9/S10/basal/other & $2(1.0) / 5(2.4) / 1(0.5) / 9(4.3)$ \\
\hline \multicolumn{2}{|l|}{ Left } \\
\hline \multirow[t]{2}{*}{$\mathrm{S} 1+2 / \mathrm{S} 3 / \mathrm{S} 1+2+3 / \mathrm{S} 4 /$ lingular } & $11(5.3) / 13(6.2) /$ \\
\hline & $27(12.9) / 1(0.5) / 15(7.2)$ \\
\hline \multirow[t]{2}{*}{ S6/S8/S10/other, n (\%) } & $13(6.2) / 9(4.3) /$ \\
\hline & $2(1.0) / 12(5.7)$ \\
\hline Operation duration, min (range) & $105(68-189)$ \\
\hline Blood loss, mL (range) & $12(0-366)$ \\
\hline Length of skin incision, $\mathrm{cm}$ (range) & $6(5-12)$ \\
\hline Margin distance, $\mathrm{mm}$ (range) & $22(5-85)$ \\
\hline \multicolumn{2}{|l|}{ Demarcation of intersegmental plane } \\
\hline By ICG, n (\%), good/poor & $184(88.0) / 25(12.0)$ \\
\hline By HFJV, n (\%), good/poor & $126(78.7) / 34(21.3)$ \\
\hline \multicolumn{2}{|l|}{ Time from injection of ICG } \\
\hline $\begin{array}{l}\text { To detection of intersegmental plane, } \mathrm{s} \text {, } \\
\text { median (range) }\end{array}$ & $15(3-60)$ \\
\hline $\begin{array}{l}\text { To maximum visualization, } \mathrm{s} \text {, median } \\
\text { (range) }\end{array}$ & $40(10-155)$ \\
\hline $\begin{array}{l}\text { To disappearance of intersegmental } \\
\text { plane, s, median (range) }\end{array}$ & $90(30-420)$ \\
\hline $\begin{array}{l}\text { Distance between HFJV and ICG-related } \\
\text { intersegmental plane, }{ }^{*} \mathrm{~mm} \text {, median } \\
\text { (range) }\end{array}$ & $+13(-18$ to +75$)$ \\
\hline \multicolumn{2}{|l|}{ Postoperative day } \\
\hline Chest tube removal, $\mathrm{d}$, median (range) & $1(1-26)$ \\
\hline $\begin{array}{l}\text { Discharge from hospital, d, median } \\
\text { (range) }\end{array}$ & $3(2-28)$ \\
\hline \multicolumn{2}{|l|}{ Postoperative morbidities, $\mathrm{n}(\%)$} \\
\hline Pulmonary fistula & $3(1.4)$ \\
\hline Bronchopleural fistula & $1(0.5)$ \\
\hline Toxic shock syndrome & $1(0.5)$ \\
\hline
\end{tabular}

ICG, Indocyanine green; HFJV, high-frequency jet ventilation. *"+10" means that the intersegmental plane depicted by HFJV spread more far beyond the plane depicted by ICG injection.

maximum visualization were significantly longer in complex segmentectomy than in simple segmentectomy $(18.5 \pm 9.5 \mathrm{vs}$ $15.6 \pm 6.9$ seconds, and $41.7 \pm 20.1$ vs $36.3 \pm 19.0$ seconds, $P=.031$ and .048 , respectively) (Table 4).

\section{Comparison by Lung Function}

Patients with FEV1/FVC $<0.7$ (obstructive lung disorder) were older than the remaining patients $(P=.015)$. For sex, smoking habit, operation duration, blood loss, length of skin incision, margin distance, and postoperative course, there was no significant difference depending on the presence or absence of obstructive lung disorder. Times from the intravenous injection of ICG to detection of the intersegmental
TABLE 3. Details of resected disease

\begin{tabular}{lc}
\hline \multicolumn{1}{c}{ Characteristic } & Value \\
\hline $\begin{array}{l}\text { Histology, } \mathrm{n}(\%) \\
\text { Lung ADC/lung SCC/other lung } \\
\text { cancer }\end{array}$ & $179(85.6) / 5(2.4) / 2(1.0)$ \\
$\begin{array}{l}\text { Metastatic cancer/other } \\
\text { malignancies/benign lesion }\end{array}$ & $12(5.7) / 5(2.4) / 6(2.9)$ \\
Radiological total lesion size, mm, \\
median (range) \\
$\begin{array}{l}\text { Pathologic total lesion size, mm, } \\
\text { median (range) }\end{array}$ \\
$\begin{array}{l}\text { Pathologic TNM classification (lung } \\
\text { cancer, } \mathrm{n}=186), \mathrm{n}(\%)\end{array}$ \\
$\begin{array}{l}\text { TisN0M0/T1miN0M0/T1aN0M0 } \\
\text { T1bN0M0/T1cN0M0/T2aN0M0 } \\
\text { T2bN0M0/T3N0M0/T3N2M0 }\end{array}$ \\
\hline $\begin{array}{l}\text { ADC, Adenocarcinoma; SCC, squamous } \\
\text { metastasis. }\end{array}$
\end{tabular}

plane and maximum visualization were significantly shorter in patients with obstructive lung disorder than in the remaining patients $(14.8 \pm 6.6$ vs $18.0 \pm 9.0$ seconds, and $34.3 \pm 16.7$ vs $40.8 \pm 20.4$ seconds, $P=.028$ and .015 , respectively) (Table 5).

\section{DISCUSSION}

ICG is a dye that has been used in medicine since the mid-1950s for a variety of applications, including the evaluation of cardiac output or hepatic function, and it is increasingly being used for intraoperative tissue perfusion. ${ }^{14}$ In this study, we showed favorable results for identifying the intersegmental plane with the use of ICG, with an $88.0 \%$ rate of good depiction of the intersegmental plane, which was greater than that by HFJV inflation (78.7\%).

Identification of the segmental bronchus has been one of the most common methods for identifying the intersegmental plane. ${ }^{2}$ However, inflation of a specific bronchus often makes it difficult to realize an inflation-deflation line, because of the collateral ventilation through the pores of Kohn, the canals of Lambert, and the direct airway anastomosis. ${ }^{2}$ Indeed, in our study the air injected by HFJV tended to spread further beyond the intersegmental plane demarcated by ICG, and detection of the inflationdeflation line was significantly worse in complex segmentectomy compared with simple segmentectomy. In contrast, the quality of ICG was not decreased significantly for cases of complex segmentectomy, or obstructive lung disease. These findings suggest that the use of ICG might contribute to find the intersegmental plane more restricted to the target segment than HFJV and can be commonly applicable in pulmonary segmentectomy regardless of the type of segmentectomy or the presence of obstructive lung disease 
TABLE 4. Comparison of patient characteristics and perioperative outcomes between simple and complex segmentectomies

\begin{tabular}{|c|c|c|c|}
\hline \multirow[b]{2}{*}{ Characteristic } & \multicolumn{2}{|c|}{ Value } & \multirow[b]{2}{*}{$P$ value } \\
\hline & $\begin{array}{l}\text { Simple segmentectomy } \\
(\mathbf{n}=\mathbf{8 9})\end{array}$ & $\begin{array}{l}\text { Complex segmentectomy } \\
(\mathrm{n}=120)\end{array}$ & \\
\hline Age at operation, $y$, mean $\pm \mathrm{SD}$ & $67.9 \pm 11.2$ & $68.0 \pm 12.0$ & .800 \\
\hline Sex, female/male, n $(\%)$ & $53(59.6) / 36(40.4)$ & $69(57.5) / 51(42.5)$ & .766 \\
\hline Smoking habit, present/absent $(\%)$ & $43(48.3) / 46(51.7)$ & $57(47.5) / 63(52.5)$ & .907 \\
\hline Operation duration, min, mean $\pm \mathrm{SD}$ & $105 \pm 18$ & $109 \pm 20$ & .169 \\
\hline Blood loss, $\mathrm{mL}$, mean $\pm \mathrm{SD}$ & $29.0 \pm 54.9$ & $23.9 \pm 40.5$ & .341 \\
\hline Length of skin incision, $\mathrm{cm}$, mean $\pm \mathrm{SD}$ & $6.0 \pm 0.7$ & $6.1 \pm 1.0$ & .692 \\
\hline Margin distance, $\mathrm{mm}$, mean $\pm \mathrm{SD}$ & $27.0 \pm 14.9$ & $21.0 \pm 10.0$ & .004 \\
\hline \multicolumn{4}{|l|}{ Preoperative pulmonary function } \\
\hline Predicted FVC $\%$, mean \pm SD & $110.7 \pm 17.4$ & $109.9 \pm 17.2$ & 697 \\
\hline $\mathrm{FEV} 1 / \mathrm{FVC}$, mean $\pm \mathrm{SD}$ & $75.0 \pm 8.1$ & $75.2 \pm 7.6$ & .795 \\
\hline Predicted $\%$ FEV1, mean \pm SD & $110.3 \pm 22.5$ & $110.1 \pm 18.9$ & .668 \\
\hline \multicolumn{4}{|l|}{ Demarcation of intersegmental plane } \\
\hline By ICG & $81(91.0) / 8(9.0)$ & $103(85.8) / 17(14.2)$ & .254 \\
\hline By HFJV & $59(86.8) / 9(13.2)$ & $67(72.8) / 25(17.2)$ & .033 \\
\hline \multicolumn{4}{|l|}{ Time from injection of ICG } \\
\hline $\begin{array}{l}\text { To detection of the intersegmental plane, } \mathrm{s} \text {, } \\
\text { mean } \pm \mathrm{SD}\end{array}$ & $15.6 \pm 6.9$ & $18.5 \pm 9.5$ & .031 \\
\hline To maximum visualization, $\mathrm{s}$, mean $\pm \mathrm{SD}$ & $36.3 \pm 19.0$ & $41.7 \pm 20.1$ & .048 \\
\hline $\begin{array}{l}\text { To disappearance of the intersegmental plane, } \\
\mathrm{s} \text {, mean } \pm \mathrm{SD}\end{array}$ & $95.5 \pm 61.5$ & $99.8 \pm 45.9$ & .064 \\
\hline $\begin{array}{l}\text { Distance between HFJV and ICG-related } \\
\text { intersegmental plane, } \mathrm{mm} \text {, mean } \pm \mathrm{SD}\end{array}$ & $13.0 \pm 13.5$ & $12.6 \pm 14.4$ & .836 \\
\hline \multicolumn{4}{|l|}{ Postoperative day } \\
\hline Chest tube removal, $\mathrm{d}$, mean $\pm \mathrm{SD}$ & $1.9 \pm 1.9$ & $1.4 \pm 1.0$ & .006 \\
\hline Discharge from hospital, d, mean \pm SD & $4.2 \pm 3.7$ & $3.7 \pm 1.6$ & .131 \\
\hline Postoperative morbidities, ${ }^{*}$ absent/present $(\%)$ & $88(98.9) / 1(1.1)$ & $116(96.7) / 4(3.3)$ & .089 \\
\hline
\end{tabular}

Statistical analyses using the $t$ test, Mann-Whitney $U$ test, or $\chi^{2}$ test, as appropriate. $S D$, Standard deviation; $F V C$, forced vital capacity; $F E V 1$, forced expiratory volume in $1 \mathrm{~s}$; $I C G$, indocyanine green; $H F J V$, high-frequency jet ventilation. *Clavien-Dindo grade $\geq 3$.

(Figure 4). This would be one of the strong points of the use of ICG.

As for the use of ICG, the median times from intravenous injection of ICG to maximum visualization and disappearance of the intersegmental plane were 40 and 90 seconds, respectively. Because the demarcation line disappears over time, the key for successful depiction of the intersegmental plane might be recognizing and marking it during the maximum visualization period.

For cases of complex segmentectomy, the times from intravenous injection of ICG to the detection and maximum visualization of the intersegmental plane were longer than those in simple segmentectomy. One possible explanation for this is that the arteries to be divided in complex segmentectomy are narrower and located in a more peripheral area compared to those in simple segmentectomy.

Interestingly, the times from intravenous ICG injection to detection and maximum visualization of the intersegmental plane were shorter in cases with obstructive lung disease, although the difference was only a few seconds. Although it is difficult to speculate on the reason for this result, it is possible that vascular remodeling along with emphysematous change or pulmonary hypertension may play some role. ${ }^{15,16}$ Considering that $12 \%$ of cases in our study did not show good demarcation of the intersegmental plane by ICG, further study would be warranted to analyze the mechanism of action of ICG.

Although this is the largest-scale report on segmentectomy using ICG, we experienced only 5 cases $(2.4 \%)$ of postoperative complications of Clavien-Dindo grade 3 or more. We also did not have problems in achieving enough margin distance using ICG. In our method, we used ICG as the main way to depict the intersegmental plane. However, we also used information on the location of the pulmonary vein and inflation-deflation line, as appropriate. Although ICG injection gives excellent results by itself, by combining it with other methods, the accuracy of surgery might have been strengthened. Through accurate identification of the intersegmental plane, poor inflation of the remaining lung, postoperative atelectasis, and imbalance of 
TABLE 5. Comparison of patient characteristics and perioperative outcomes according to pulmonary function

\begin{tabular}{|c|c|c|c|}
\hline \multirow[b]{2}{*}{ Characteristic } & \multicolumn{2}{|c|}{ Value } & \multirow[b]{2}{*}{$P$ value } \\
\hline & $\overline{\text { FEV1/FVC } \geq 0.7(n=163)}$ & FEV1/FVC $<0.7(n=46)$ & \\
\hline Age at operation, $\mathrm{y}$, mean $\pm \mathrm{SD}$ & $66.8 \pm 11.7$ & $71.9 \pm 10.5$ & .015 \\
\hline Sex, female/male, n (\%) & $96(58.9) / 67(41.1)$ & $26(56.5) / 20(43.5)$ & .773 \\
\hline Smoking habit, present/absent, n (\%) & $73(44.8) / 90(55.2)$ & $27(58.7) / 19(41.3)$ & .095 \\
\hline Operation duration, min, mean $\pm \mathrm{SD}$ & $106 \pm 18$ & $112 \pm 21$ & .091 \\
\hline Blood loss, $\mathrm{mL}$, mean $\pm \mathrm{SD}$ & $24.4 \pm 42.9$ & $32.0 \pm 59.9$ & .751 \\
\hline Length of skin incision, $\mathrm{cm}$, mean $\pm \mathrm{SD}$ & $6.0 \pm 0.8$ & $6.2 \pm 1.2$ & .526 \\
\hline Margin distance, $\mathrm{mm}$, mean $\pm \mathrm{SD}$ & $23.6 \pm 12.6$ & $23.2 \pm 13.1$ & .781 \\
\hline Preoperative predicted $\mathrm{FVC} \%$, mean $\pm \mathrm{SD}$ & $109.6 \pm 16.4$ & $112.8 \pm 19.8$ & .288 \\
\hline \multicolumn{4}{|l|}{ Demarcation of intersegmental plane } \\
\hline By ICG, good/poor, n (\%) & $147(90.2) / 16(9.8)$ & $37(80.4) / 9(19.6)$ & .072 \\
\hline By HFJV, good/poor, n (\%) & $99(79.2) / 26(20.8)$ & $27(77.1) / 8(22.9)$ & .793 \\
\hline \multicolumn{4}{|l|}{ Time from injection of ICG } \\
\hline To detection of the intersegmental plane, $\mathrm{s}$, mean $\pm \mathrm{SD}$ & $18.0 \pm 9.0$ & $14.8 \pm 6.6$ & .028 \\
\hline To maximum visualization, $\mathrm{s}$, mean $\pm \mathrm{SD}$ & $40.8 \pm 20.4$ & $34.3 \pm 16.7$ & .015 \\
\hline $\begin{array}{l}\text { To disappearance of the intersegmental plane, } \mathrm{s} \text {, } \\
\text { mean } \pm \mathrm{SD}\end{array}$ & $102.0 \pm 56.6$ & $83.4 \pm 35.3$ & .090 \\
\hline $\begin{array}{l}\text { Distance between HFJV and ICG-related intersegmental } \\
\text { plane, } \mathrm{mm}, \text { mean } \pm \mathrm{SD}\end{array}$ & $13.2 \pm 14.1$ & $11.3 \pm 13.5$ & .709 \\
\hline \multicolumn{4}{|l|}{ Postoperative day } \\
\hline Chest tube removal, $\mathrm{d}$, mean $\pm \mathrm{SD}$ & $1.9 \pm 1.9$ & $1.4 \pm 1.0$ & .006 \\
\hline Discharge from hospital, $\mathrm{d}$, mean $\pm \mathrm{SD}$ & $4.2 \pm 3.7$ & $3.7 \pm 1.6$ & .131 \\
\hline Postoperative morbidities, absent/present, $\mathrm{n}(\%)^{*}$ & $160(98.2) / 3(1.8)$ & $44(95.7) / 2(4.3)$ & .326 \\
\hline
\end{tabular}

Statistical analyses using the $t$ test, Mann-Whitney $U$ test, or $\chi^{2}$ test, as appropriate. $F E V I$, Forced expiratory volume in $1 \mathrm{~s} ; F V C$, forced vital capacity; $S D$, standard deviation; $I C G$, indocyanine green; $H F J V$, high-frequency jet ventilation. *Clavien-Dindo grade $\geq 3$.

pulmonary vessel flow will be reduced, which could contribute to a fair postoperative course. Considering the low risk for adverse side effects, the use of ICG is considered to be beneficial in pulmonary segmentectomy.
This study has some limitations. First, there should be some selection bias, depending on the availability of the instruments for ICG and the patient condition. Second, patients with poor pulmonary function might have a

\section{Indocyanine green imaging for pulmonary segmentectomy}

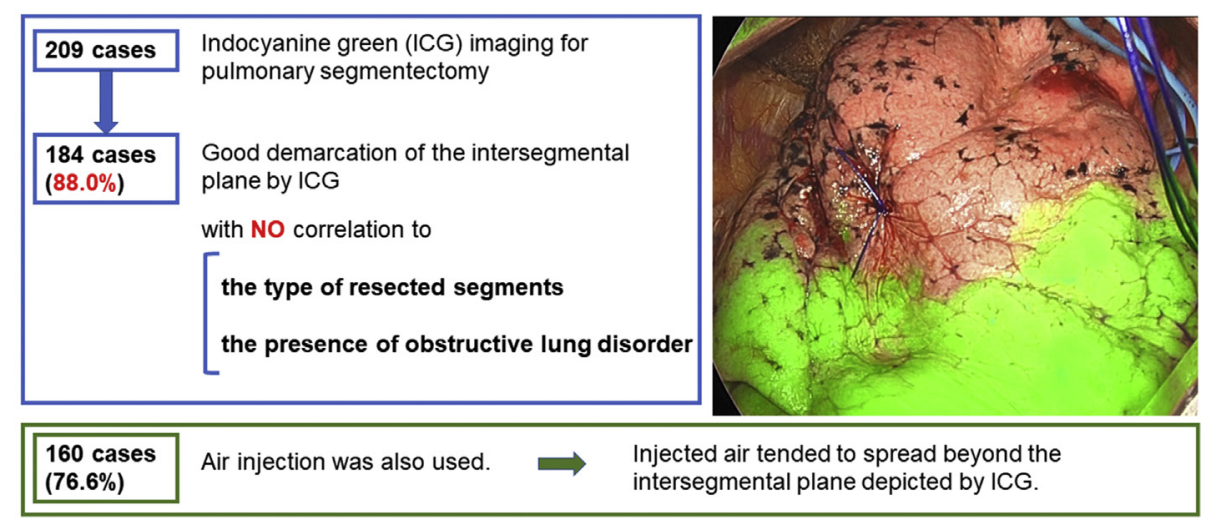

The use of ICG is a feasible and safe method regardless of the extent of resected segments or pulmonary function.

ICG, indocyanine green

FIGURE 4. We showed favorable results for identifying the intersegmental plane with the use of ICG, with an $88.0 \%$ rate of good depiction of the intersegmental plane. The use of ICG might contribute to find the intersegmental plane more restricted to the target segment than HFJV, and can be commonly applicable in pulmonary segmentectomy regardless of the type of segmentectomy or the presence of obstructive lung disease. 
tendency to undergo wedge resection rather than segmentectomy. The definitive criteria for deciding on the application of either segmentectomy or wedge resection were not settled, and therefore some selection bias for patients cannot be avoided. Third, regarding malignant tumors, local recurrence and survival should be investigated before we can draw any definitive conclusions. Our study shows only short-term outcomes after surgery. Fourth, delineation by ICG was often winding. We needed to staple the intersegmental plane straight on the approximate line, and this is one of the limitations of the use of ICG. Fifth, we did not have detailed data on jet ventilation. It would be beneficial if we could compare selective ventilation to ICG injection as a measure of efficacy. Sixth, although at least 2 surgeons evaluated the timings of the visualization of the intersegmental plane and its peak after the injection of ICG, this evaluation might harbor some ambiguity. Seventh, as this is a retrospective study, there should be an even greater possibility of selection bias. For further productive analyses, a prospective study will be warranted.

In conclusion, we showed in our large-scale cohort that pulmonary segmentectomy using systemic ICG injection was a feasible and safe operative method, from the perspective of accurate demarcation of the intersegmental plane, with a fair postoperative course. The use of ICG might demarcate the intersegmental plane more restricted to the target segment compared with air injection. As segmentectomy becomes a standard operative procedure, ICG could be a widely applicable modality.

\section{Conflict of Interest Statement}

The authors reported no conflicts of interest.

The Journal policy requires editors and reviewers to disclose conflicts of interest and to decline handling or reviewing manuscripts for which they may have a conflict of interest. The editors and reviewers of this article have no conflicts of interest.

We thank members of the Division of Biostatistics at National Cancer Center for offering fruitful opinions and suggestions on the statistical method.

\section{References}

1. Nakagawa K, Watanabe SI, Kunitoh H, Asamura H. The lung cancer surgical study group of the Japan clinical oncology group: past activities, current status and future direction. Jpn J Clin Oncol. 2017;47:194-9.

2. Andolfi M, Potenza R, Seguin-Givelet A, Gossot D. Identification of the intersegmental plane during thoracoscopic segmentectomy: state of the art. Interact Cardiovasc Thorac Surg. 2020;30:329-36.

3. Liu Z, Yang R, Cao H. Near-infrared intraoperative imaging with indocyanine green is beneficial in video-assisted thoracoscopic segmentectomy for patients with chronic lung diseases: a retrospective single-center propensity-score matched analysis. J Cardiothorac Surg. 2020;15:303.

4. Sekine Y, Ko E, Oishi H, Miwa M. A simple and effective technique for identification of intersegmental planes by infrared thoracoscopy after transbronchial injection of indocyanine green. J Thorac Cardiovasc Surg. 2012;143: 1330-5.

5. Sun Y, Zhang Q, Wang Z, Shao F, Yang R. Is the near-infrared fluorescence imaging with intravenous indocyanine green method for identifying the intersegmental plane concordant with the modified inflation-deflation method in lung segmentectomy? Thorac Cancer. 2019;10:2013-21.

6. Tarumi S, Misaki N, Kasai Y, Chang SS, Go T, Yokomise H. Clinical trial of video-assisted thoracoscopic segmentectomy using infrared thoracoscopy with indocyanine green. Eur J Cardiothorac Surg. 2014;46:112-5.

7. Guigard S, Triponez F, Bédat B, Vidal-Fortuny J, Licker M, Karenovics W. Usefulness of near-infrared angiography for identifying the intersegmental plane and vascular supply during video-assisted thoracoscopic segmentectomy. Interact Cardiovasc Thorac Surg. 2017;25:703-9.

8. Pischik VG, Kovalenko A. The role of indocyanine green fluorescence for intersegmental plane identification during video-assisted thoracoscopic surgery segmentectomies. J Thorac Dis. 2018;10:S3704-11.

9. Asamura H. Minimally invasive open surgery approach for the surgical resection of thoracic malignancies. Thorac Surg Clin. 2008;18:269-73. vi.

10. Mun M, Okumura S, Nakao M, Matsuura Y, Nakagawa K. Indocyanine green fluorescence-navigated thoracoscopic anatomical segmentectomy. J Vis Surg. 2017;3:80.

11. Matsuura Y, Mun M, Ichinose J, Nakao M, Nakagawa K, Okumura S. Recent fluorescence-based optical imaging for video-assisted thoracoscopic surgery segmentectomy. Ann Transl Med. 2019;7:32.

12. Clavien PA, Barkun J, de Oliveira ML, Vauthey JN, Dindo D, Schulick RD, et al. The Clavien-Dindo classification of surgical complications: five-year experience. Ann Surg. 2009;250:187-96.

13. Celli BR, MacNee W, Force AET. Standards for the diagnosis and treatment of patients with COPD: a summary of the ATS/ERS position paper. Eur Respir J. 2004;23:932-46.

14. Reinhart MB, Huntington CR, Blair LJ, Heniford BT, Augenstein VA. Indocyanine green: historical context, current applications, and future considerations. Surg Innov. 2016;23:166-75.

15. Zuo L, Nogueira L, Hogan MC. Reactive oxygen species formation during tetanic contractions in single isolated Xenopus myofibers. J Appl Physiol (1985). 2011;111:898-904

16. Lu Q, Gottlieb E, Rounds S. Effects of cigarette smoke on pulmonary endothelial cells. Am J Physiol Lung Cell Mol Physiol. 2018;314:L743-56.

Key Words: pulmonary segmentectomy, indocyanine green in pulmonary, near-infrared imaging 